\title{
Using Calculator-Assisted Instruction to Enhance Low-Achievers in Learning Number Sense: A Case Study of Two Fifth Graders in Taiwan
}

\author{
Der-Ching Yang ${ }^{1} \&$ Yung-Chi Lin ${ }^{2}$ \\ ${ }^{1}$ Graduate Institute of Mathematics and Science Education, National Chiayi University, Chiayi, Taiwan \\ ${ }^{2}$ Graduate Institute of Science Education, National Changhua University of Education, Changhua, Taiwan \\ Correspondence: Yung-Chi, Lin, No.1, Jin-De Road, Changhua 500, Taiwan. Tel: 886-972-031-270. E-mail: \\ yclin@cc.ncue.edu.tw
}

Received: January 15, 2015

Accepted: February 5, 2015

Online Published: May 29, 2015

doi:10.5539/jel.v4n2p64

URL: http://dx.doi.org/10.5539/jel.v4n2p64

\begin{abstract}
The purpose of this study was to use calculator-assisted instruction to help two fifth-grade low-achievers learn number sense. The research process includes three stages: (1) pre-test interview to detect what kinds of number sense the students did not have; (2) calculator-assisted instruction to help them develop number sense; and (3) post-test interview to examine if their number sense had improved. The results showed that students successfully developed two kinds of number sense abilities they did not have in the pre-test interview. However, they failed to develop the number sense ability of using a benchmark number to make an estimation. Generally, this study illustrated that these two low-achievers could learn number sense from calculator-assisted instruction.
\end{abstract}

Keywords: calculator, fifth graders, number sense

\section{Introduction}

Number sense has been recognized as an important topic in school mathematics (Maertens, Reynvoet, De Smedt, \& Elen, 2014; McIntosh, Reys, \& Reys, 1992; Reys \& Yang, 1998; Siegler \& Ramani, 2011; Yang \& Wu, 2010; Yang, 2005; Yang \& Lai, 2013). The Principles and Standards for School Mathematics (National Council of Teachers of Mathematics [NCTM], 2000) even indicates that developing number sense is central to the number and operations standard. Number sense is defined as making sense of numbers, operations and their relationships (Reys \& Yang, 1998; McIntosh et al., 1992; Witzel, Ferguson, \& Mink, 2012). Number sense belongs to conceptual knowledge and contains both low- and higher-order thinking (Jordan, Kaplan, Nabors, \& Locuniak, 2006). Students with number sense can do computations in flexible or creative ways and have better intuition in doing quantitative reasoning (Olanoff et al., 2014). For example, one can estimate the result of $299 \times 0.99$ is quite close to 300 without using the written computation method because 0.99 is close to $1 ; 299$ is close to 300 ; and $300 \times 1$ will be 300 .

In general, there are four components defined in number sense (Reys \& Yang, 1998; Yang, 2005): (1) recognizing relative number size; (2) using multiple representations of number and operations; (3) judging the reasonableness of estimates of computed results; and (4) recognizing the relative effect of operations on numbers. Within these four components, Taiwanese students perform worse in components (3) and (4) (Yang \& Wu, 2010). Therefore, in this study, our target number sense is focused on the last two components. More specifically, these are: (3.1) using a benchmark number to make estimation; (4.1) discovering the relation between division and numbers; (4.2) recognizing number patterns; and (4.3) discovering the relation between multiplication and numbers.

Researchers have shown their positive attitude toward using calculators in the mathematics classroom for over twenty years (e.g., Bouck, Joshi, \& Johnson, 2013; Hembree \& Dessart, 1986). Many researchers believe using calculators can benefit students' mathematics learning. For example, studies show that using a calculator can foster students' concept development, enhance their problem solving ability, reduce computation errors and increase their motivation (Bouck, Joshi, \& Johnson, 2013). In particular, for those students who have low computation performance, using a calculator can better improve their conceptual learning (Gray \& Pitta, 1997). 
As we have mentioned, number sense has been thought of as a kind of mathematics thinking with both lowerand higher-order thinking (Jordan, Kaplan, Nabors, \& Locuniak, 2006). It involves understanding not only the basic meaning of numbers and operations but also quantitative reasoning, pattern awareness and fluency and flexibility in operations. From the cognitive load theory perspective, one's working memory is limited (Sweller, Van Merrienboer, \& Paas, 1998). However, when students try to learn number sense, they need to learn both basic meaning of numbers and operations (e.g., algorithms) and other higher-order thinking (e.g., pattern awareness). If one is still struggling to learn the basic operation knowledge, to learn the higher-order thinking in number sense may be too much cognitive load for him or her. Therefore, by using a calculator in instruction can help these students to reduce their working memory load and then help them to develop their higher-order thinking in number sense.

From the above discussion, using a calculator may contribute to low-achievers' number sense learning. However, there is still little research directly addressed on this issue. It is unclear what kind of calculator activities can actually help low-achievers' number sense learning. In addition, we are also unclear about students' learning process in these calculator activities. Most importantly, in the Taiwanese mathematics classroom, using calculators is still forbidden. We have little information about the ways in which Taiwanese students can take advantage of using (four function) calculators in their number sense learning. Therefore, the purpose of this study was to investigate how two Taiwanese fifth-grade low-achievers learn number sense through the design of calculator-assisted instruction.

\section{Method}

\subsection{Research Design}

The research design of this study is a case study containing three stages: (1) pre-test interview, (2) calculator-assisted instruction and (3) post-test interview in order to examine whether the designed calculator activities could actually help the participants learn number sense. The research process included the following: selecting two low-achievers; developing four pre- and post-interview problems that corresponded with four number sense components defined in this study; conducting interviews and instruction; analyzing the collected data and writing a report for them.

\subsection{Participants}

In the process of selecting two low-achievers, we first found a fifth-grade class whose teacher was willing to collaborate with this study. This class was a heterogeneous class that consisted of all kinds of learners with different mathematics performance. Then, the nine low-achievers were classified according to their previous mathematics grades (from first-grade to fourth-grade), which were the lowest quartile in the class. We then interviewed these nine students with some common computation problems from the textbook they were learning (e.g., estimate whether $94,179 \div 2$ is greater or less than 23,715). In addition, we also consulted with their mathematics teacher in order to further understand their mathematics performance in the classroom. Finally, the two low-achievers, Howard and Jane (pseudonyms), were selected. They both demonstrated poor arithmetic ability but good oral expression ability. We thought this might be more helpful in our interview data collection.

\subsection{Research Instrument}

As we mentioned in the earlier section, the four number sense sub-components were defined in this study: (3.1) using a benchmark number to make estimation (Benchmark); (4.1) discovering the relation between division and numbers (RDivision); (4.2) recognizing number patterns (Pattern); and (4.3) discovering the relation between multiplication and numbers (RMultiplication). According to the four sub-components, four mathematics problems were designed to examine if Howard and Jane possessed the relevant concepts. The four problems, corresponding to the four sub-components respectively, are as follows:

Problem 1 (Benchmark): Before the mid-term examination, Andrew's parents set a reward to encourage him to study harder: If his total grades of the six subjects were above 450, Andrew would win a present from his mother; if above 550, his father would give him an extra present. What was the lowest average grade Andrew had to get to win the extra present? What was the highest average grade Andrew would get if he wins nothing? What would be the average grade Andrew must attain to win only one present?

Problem 2 (RDivision): What is the relationship between the numerator and the denominator when the quotient is greater than, equal to and less than 1 ?

Problem 3 (Pattern): Find (a)15×2, 15×4, 15×8; (b) $24 \times 5,24 \times 15,24 \times 25$; (c) $555 \times 12,555 \times 36,555 \times 72$. 
(4) Problem 4 (RMultiplication): Which of the following is the largest: $15 \times 0.699,2 \times 0.699,18 \times 0.699,16 \times$ 0.699 ?

Referring to Wheatley and Clements (1990), and Waits and Demana (1998), four corresponding activities were also designed (Table 1). During the development process, a mathematics educator and two senior mathematics teachers with more than ten years' teaching experience (per person) were involved to confirm the content validity.

Table 1. Calculator activities

\begin{tabular}{|c|c|c|}
\hline Activity & Content & Number Sense \\
\hline Range Game & $\begin{array}{l}\text { Finding the multiples of a given number that will fall in a given } \\
\text { range (e.g. starting from } 20 \text { with target area of } 250-430 \text { ). }\end{array}$ & $\begin{array}{l}\text { Benchmark } \\
\text { (Problem 1) }\end{array}$ \\
\hline Number Guessing & $\begin{array}{l}\text { Instructor A picks a number } x \text { in his mind; student B guesses the } \\
\text { number as } y \text { and keys it into the calculator, then A shows B the } \\
\text { answer of } y \div x \text {. Duplicating the procedures by modifying the } \\
\text { guessing number } y \text {, until B finds the number } x \text {. }\end{array}$ & $\begin{array}{l}\text { RDivision } \\
\text { (Problem 2) }\end{array}$ \\
\hline Observing the Pattern & $\begin{array}{l}\text { Discovering the regularity of the products of two numbers in a } \\
\text { series (e.g. } 15 \times 4,30 \times 4) \text {. }\end{array}$ & $\begin{array}{l}\text { Pattern } \\
\text { (Problem 3) }\end{array}$ \\
\hline $\begin{array}{l}\text { Multiplying Your } \\
\text { Expectation }\end{array}$ & $\begin{array}{l}\text { Estimating the products of two numbers which are greater or less } \\
\text { than } 1 .\end{array}$ & $\begin{array}{l}\text { RMultiplication } \\
\text { (Problem 4) }\end{array}$ \\
\hline
\end{tabular}

\subsection{Research Procedure}

One-on-one interviews were conducted during the school one-hour lunchtime for one day a week over ten weeks. One week was for the pre-test interview; eight weeks were for calculator-assisted instruction and one week was for the post-test interview. In the pre-test interview, Howard and Jane were asked to answer the pre-test problems without using a calculator and there was no time limit. The purpose of the pre-test interview was to identify what kinds of number sense they did not possess. The interviewer might ask questions for clarifying their understanding of the participants' thinking when the interviewer felt needed. After analyzing and obtaining their pre-test interview results, the second author then conducted the calculator-assisted instruction with Howard and Jane individually to help them develop the number sense. In the instruction stage, we adopted the constructivist perspective of teaching with a calculator (Groves, 1994) as our main teaching strategy, in which three major steps were included: (a) Discovery: to allow children to explore the questions freely by using a calculator. (b) Meaning: to make mathematics meanings the focus of attention. (c) Generalization: to guide children to develop new concepts.

Finally, the same interview problems were used in the post-test interview to determine if the calculator-assisted instruction could successfully help the two participants learn number sense. They were prohibited to use a calculator in the post-test interview again.

There might be some question of the students remembering some of the pre-test problems when taking the post-test interview. However, we did not consider this a possibility since the way the study was conducted it was not intended to motivate the participants to do so. In addition, the post-test interview took place ten weeks later than the pre-test interview. We believe these fifth graders cannot remember the pre-test problems well if they did not intend to remember the pre-test problems. However, we paid attention to whether it might happen in the post-test interview.

It should be noted that the calculator used in this study was a simple function calculator that only can add, subtract, multiply, and divide. Compared to a graphing calculator, although it can not record all the numbers which one has entered on the screen, it is cheaper, easier to use, and easier to obtain in Taiwan. To make up for the deficiency, the instructor simply provided worksheets that allowed students to record each input and result during the calculator-assisted instruction.

\section{Results}

Table 2 summarizes Howard and Jane's performance in the pre-test and post-test interview. It should be noted that the main purpose of the study was to examine whether the designed instruction activities could help Howard 
and Jane learn number sense. Therefore, since both of them passed Problem 2 (P2) in the pre-test interview, "Number Guessing" (corresponding to P2) was not conducted with them and P2 was not given in the post-test interview either.

Table 2. Howard and Jane's performances in the pre-test and post-test interview

\begin{tabular}{lllllllll}
\hline & \multicolumn{1}{c}{ Pre-test } & \multicolumn{7}{c}{ Post-test } \\
\hline Howard & P1 & P2 & P3 & P4 & P1 & P2 & P3 & P4 \\
Jane & $\times$ & 0 & $\times$ & $\times$ & $\times$ & - & 0 & $\circ$ \\
\hline
\end{tabular}

Note. $\circ$, pass; $\times$, did not pass; - , no need to examine

\subsection{Pre-Test Interviews}

In the pre-test, Howard and Jane both passed Problem 2 (P2) by giving the correct answer, which was that when the numerator and the denominator are the same, the quotient will be 1; when the numerator is greater than the denominator, the quotient will be greater than 1; when the numerator is less than the denominator, the quotient will be less than 1. However, they both could not use the number sense approach to answer the other three problems. For example, when confronted with Problem 3 (Figure 1), Howard and Jane immediately used paper-and-pencil computation to solve the questions but could not use the number sense approach strategies. The following was an episode of the interview with Howard when he was answering Problem 3:

Instructor: How do you solve the following three questions?

(1) $24 \times 5=\quad$ (2) $24 \times 15=\quad$ (3) $24 \times 25=$

Howard: (writing the answers by using paper-and-pencil computation immediately)

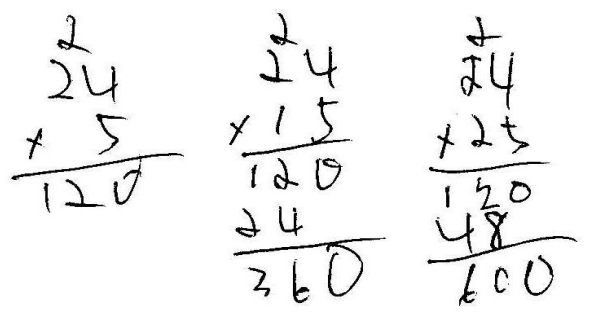

Figure 1. Paper-and-pencil computation used by Howard

Instructor: Jolly good, you made correct answers. But do you have any other strategies?

Howard: (thinking for about 5 seconds) No, I don't.

Instructor: Did you notice that there are three questions in this problem?

Howard: Yes.

Instructor: And how did you think about it?

Howard: What should I think?

Instructor: You could observe their relationship.

Howard: ...... (Pondering for a while, and saying nothing)

Instructor: So can you think of any other strategies now?

Howard: No! (Shaking his head)

\subsection{Calculator-Assisted Instruction}

In the instruction stage, we only conducted three calculator activities that were corresponding to Problem 1, 3, and 4 in the pre-test interview, since both Howard and Jane solved Problem 2 successfully in the pre-test interview. During the instruction process, we found that Howard and Jane were able to use their calculators to 
experiment with numbers and operations and construct their own meanings under appropriate guidance. The experience of conjecturing, verifying and reasoning may be quite useful for children's number sense learning.

For example, when Howard was engaged in the activity "Observing the Pattern,", he tried to analyze the relationship between the results of $15 \times 4$ and $45 \times 16$. At first, he easily got $15 \times 4=60,45 \times 16=720$ by using his calculator. Moreover, he already knew that if the multiplier or multiplicand were multiplied by a certain number, the result would also be multiplied by the same number in the early instruction period. To pursue his inquiry, he began to hypothesize that the result 720 came from $(15 \times 4) \times 7$. Because he knew 45 is three times of 15 and 16 is four times of 4 , he thought that three times and four times combined together should be seven times. However, this reasoning is not correct. When using a calculator to check the answer of $60 \times 7$, which is 420 but not 720 , he got stuck for a long time. He unconsciously punched several multiplications into the calculator but got nothing helpful (such as $16 \times 1,16 \times 2 \ldots$ ). In the meantime, the instructor decided to intervene and gave him a hint. The instructor suggested to Howard that he examined the relationship between their results (60 and 720). Following up this suggestion, he tried to use his calculator to check the answer of $720 \div 60$ and began to think about the relationship between 3, 4, and 12. It did not take long for Howard to finally realize that 3 should be "multiplied by" 4 to get " 12 ", but not "adding them up" to get "7" and he continuously applied the same pattern to examine other multiplication questions such as $15 \times 4$ and $495 \times 36$ to make sure that this pattern is always true with the same kind of questions.

The following are two episodes of the teaching activities with Jane and Howard, respectively. It can be noted in the first episode with Jane in the activity "Observing the Pattern" that following the instructor's guidance to use a calculator, Jane was able to observe the pattern of the series of questions (relation of multiples) and progressively applied it to answer the subsequent questions. She even tried to use mental computation in the end of the episode, although the answer was incorrect. This seems to imply that she became more confident with computation with the calculator in hand.

(Jane was asked to answer the following series of questions: $15 \times 4,30 \times 4,45 \times 16,15 \times 108,375 \times 8,375 \times 48$, $1395 \times 16,15024,120 \times 16,495 \times 36$. In the beginning, she obtained all the products by using a calculator.)

Interviewer: Well, you just used the calculator to get all these answers. Perhaps mental computation is more useful for some of the questions.

Jane: I'm not good at mental computation.

Instructor: OK. Have a look at $15 \times 4=60$ and $30 \times 4=120$. Do you notice any relation between the questions and their answers?

Jane: (Keying in 30 $\div 15$ ) They are multiples!

Instructor: What multiples? Can you explain it more clearly?

Jane: Just like "30 is double of 15"!

Instructor: Right! How about the answer?

Jane: (Keying in $120 \div 60$ ) It's double as well! (She means 120 is double of 60 )

Instructor: If $15 \times 4=60$ is given, can you answer $30 \times 4$ ?

Jane: Let me think.

(Keying in $30 \times 1,30 \times 2,30 \times 3 \ldots, 15 \times 1,15 \times 2, \ldots$ without noticing the relation)

Instructor: You can try to think of the relation of these multiples.

Jane: (Keying in 60×2) Yes! I got it! It's 120 .

Instructor: Where does your answer come from?

Jane: Since 30 is double of 15, it should be the answer. Therefore, 60 multiplied by 2 makes 120 .

Instructor: Great! Let's try one more question, OK? If given $15 \times 4=60$, can you answer $15 \times 108$ ?

Jane: Do I need to apply the same strategy?

Instructor: Yes, if you think it's useful.

Jane: OK. Let me see. (Trying to key in $108 \div 4$ and obtaining 27 by using the calculator) 108 is 27 multiplied by 4 , so the answer of $15 \times 108$ must be 60 multiplied by 27 .

Instructor: Can you find out how much it is? 
Jane: No problem! (Using the calculator to count $60 \times 27$ ) 1620 .

Instructor: O.K. Now can you count $375 \times 48$ if given $375 \times 8=3000$ ?

Jane: (Keying in the calculator $48 \div 8$ and obtaining 6) 6 times. So the answer of $375 \times 48$ must be 6 times of 3000 , it's 1800 (using mental calculation.).

Instructor: How come the answer of $375 \times 48$ is less than $375 \times 8(=3000)$ ?

Jane: (Pondering for a while and using a calculator to check the answer) Aha! I see. There's a zero missing.

Howard's performance in the "Range Game" activity is also worthy of mention. The activity was related to finding the multiples of a given number (e.g., 20) that will fall in a given range (e.g., 250-430). At the beginning of the instruction, Howard was just trying to compute $20 \times 1,20 \times 2,20 \times 3, \ldots$, etc. (by using a calculator). The instructor then posed some probing questions to encourage him to use a more efficient method. Thus, Howard started to change his strategy by using $20 \times 10$ as a benchmark to estimate possible answers. The following conversation took place at the end of the instruction. Howard finally became more skillful at finding benchmarks to conjecture the answers.

(The question was "What are the multiples of 25 that will fall in the range 230-590?")

Howard: (Trying to key in $25 \times 10$ and obtaining 250 , and then murmuring to himself...) 10, 11, 12, let's try 20 (Keying in $25 \times 20$ ). Yah! It works. So 21,22 , (Keying in $25 \times 22$ ) 22 is 550 , so we could only have one more, 23 . That's all.

Instructor: How do you know 23 is one of the numbers without checking the answer with the calculator?

Howard: Because $25 \times 20$ is 500 . Then adding 50 we get 550 . So 21,22 are the answer (he seemed to recognize that adding one on the multiplier, the product would increase by 25). Then I add 25 to 550 and get 575 . It also works. But adding another 25 will make it 600 and that's over 590 already. Therefore, I know 23 is the biggest number.

Instructor: How do you know the relationship between products and multipliers? (What the interviewer means is that if Howard adds 1 on the multiplier, the product will increase by 25.)

Howard: I know it from the earlier trial in the range game. I observed the changes of the results when examining many multiplications, such as $25 \times 1,25 \times 2,25 \times 3$, by using the calculator. Then I found what happened to the operation.

Instructor: Brilliant! But how do you know that 10 is the smallest number in the answer?

Howard: $25 \times 10$ is just adding a zero to 25 . But $250-25$ is ... (Pondering a while then using mental computation) 225. It's less than 230 . So 10 is the smallest one.

\subsection{Post-Test Interviews}

After the eight weeks of instruction, Howard and Jane were given the same problems used in the pre-test interview except Problem 2 for the post-test interview. They both passed Problems 3 and 4 by using a number sense approach, but failed in Problem 1 again. This seems to reveal that both of them have developed the number sense ability to decompose and integrate numbers to use multiple and flexible strategies, as well as discovering the relationship between multiplication and numbers after receiving calculator-assisted instruction. The following conversation happened when Howard tried to solve Problem 3 in the post-test interview. Compared with his former performance in the pre-test interview (see the earlier section), Howard was able to observe the pattern and to use the relationship to consider the whole series of questions this time.

Interviewer: Can you do this series of questions? $(15 \times 2=, 15 \times 4=, 15 \times 8=)$

Howard: 30, 60, 120. (Writing down the answers immediately)

Interviewer: Very good! Could you tell me how you can do that so quickly?

Howard: Just because 15 times 2 is 30,4 is double of 2, thus 30 times 2 is 60 . And next is the same, 60 times 2 is 120.

\section{Discussion}

\subsection{The Complex Word Problem Still Caused Difficulty with the Two Low-Achievers in Mathematization}

For the two research participants, Howard and Jane, their performance in the post-test interview appeared to exhibit better number sense than in the pre-test interview. However, both Howard and Jane did not solve Problem 1 successfully (corresponding to the "Range Game" activity) in the post-test interview: this result was 
beyond our expectation. It seems that they both had developed the ability to find a benchmark to make an estimation in the "Range Game" instruction. The possible reason for their failure might be due to the complexity of Problem 1, which is a word problem. For fifth-grade students, word problems are usually more challenging than pure computation problems. In addition, Problem 1 was not the common word problem that usually appeared in Howard and Jane's textbooks (Taiwanese textbooks do not have many estimation problems). We suspected that both low-achievers (Howard and Jane) were struggling hard to mathematize the problem context into a mathematics problem, but unfortunately they were stuck in the procedure of mathematization and unable to apply the ability of finding a benchmark to make estimation successfully. This interpretation and analysis could also be applied to the result that Howard and Jane were able to answer Problems 3 and 4 (corresponding to "Observing the Pattern" and "Multiplying Your Expectation") in the post-test interview. Since the two problems were not within the context of a word problem situation, the students were able to focus their attention on dealing with the computation without having to mathematize the problem context first.

\subsection{Using a Calculator Can Motivate Student's Learning of Mathematics}

One of the main reasons restraining young children from successfully learning mathematics should be the abstractions and formalism of mathematics. Therefore, providing something that can be manipulated for the students to "do" mathematics is important. A calculator is just a tool that students, even the low-achievers, can easily manipulate. For these two participants, using a calculator to learn mathematics was a brand-new experience. They both greatly appreciated the new way of learning, expressing that using a calculator is like playing a game. In the instructional stage, they did not only show a high level of motivation but also could focus on the problem solving procedures more efficiently. It has generally been agreed among mathematics educators that playing games usually makes learning fun and increases students' willingness to learn mathematics (Vapumarican \& Kapur, 2012). The research results could suggest that calculators should be a catalyst for this to happen. However, playing mathematics games should target "learning mathematics" not "playing games". Hence, to prevent students from putting the emphasis on the "playing" aspect, the teacher's timely guidance and control play an important role.

\section{Conclusions}

This study focused on using calculator-assisted activities to enhance low-achievers' number sense. Even though the two students were having difficulties in arithmetic before participating in this study, after receiving the calculator-assisted teaching, they showed better number sense knowledge on Problems 3 and 4 in the post-test interview. Although they failed Problem 1, they still revealed they had developed the ability to find a benchmark to make an estimation in the Range Game activity. During the research period, we found that they were able to use their calculators widely to explore, especially to experiment with numbers and operations, and also to construct their own meanings. Through the calculator-assisted approach, they were more able to notice the whole problem-solving process and to interpret their answers. These results might confirm that the presence of a calculator provides a richer learning environment to foster low-achievers' learning number sense, as well as to remove the need of focusing on counting procedures and providing a powerful understanding of symbols (Walcott \& Stickles, 2012). Inasmuch as the evidence that the calculator-assisted instruction could help low-achievers develop number sense, it might be reasonable to infer that the calculator-assisted teaching approach would also be advantageous to high- or middle-achievers.

Based on the research results, the positive indications suggest that calculator-assisted instruction might enhance the two research participants' learning number sense, but it should be noted that the calculator is definitely not a panacea. Teachers play an important role in the instruction process. First, well-organized activities have to be designed in advance and not all mathematics topics are appropriate for calculator-assisted instruction (e.g., teaching some basic facts). Research evidence suggests that the calculator is suitable for use when exploring, conjecturing, and experimenting with numbers and operations. Additionally, teachers need to foster the skill of posing probing questions to guide students in concentrating on mathematical problem solving. Teachers also must allow students to know that a calculator cannot replace their own brainpower, and they need to make decisions about what numbers and operations should be used. Thus, teachers must have the instructional goals in hand for a given unit or lesson to decide whether and how to incorporate a calculator in students' learning.

Although this study was conducted with only two participants and in the non-regular mathematics classroom (during lunchtime), we believe that the calculator activities could also be applied to regular classroom teaching with the entire class. The key point is that these activities should provide sufficient opportunities and information for students to explore. Classroom management will become more critical while conducting calculator-assisted instruction with the entire class. The calculator is simply an auxiliary tool and the teacher's role cannot be absent 
in calculator-assisted instruction. A teacher's timely intervention and guidance will help all students' mathematics inquiry proceed more efficiently in calculator-assisted instruction.

\section{Acknowledgments}

This paper is part of a research project supported by the NSC, Taiwan with grant no. MOST 102-2511-S-415-002-MY3. Any opinions expressed here are those of the authors and do not necessarily reflect the views of the MOST, Taiwan.

\section{References}

Bouck, E. C., Joshi, G. S., \& Johnson, L. (2013). Examining calculator use among students with and without disabilities educated with different mathematical curricula. Educational Studies in Mathematics, 83(3), 369-385. http://dx.doi.org/10.1007/s10649-012-9461-3

Gray, E. M., \& Pitta, D. (1997). Changing Emily’s images. Mathematics Teaching, 161, 38-51.

Groves, S. (1994). Calculators: A learning environment to promote number sense. Paper presented at the American Educational Association Research Association 1994 Annual Meeting. New Orleans.

Hembree, R., \& Dessart, D. J. (1992). Research on calculators in mathematics education, In J. T. Teey (Ed.), Calculators in mathematics education: 1992 yearbook of the National Council of Teachers of Mathematics (pp. 22-31). Reston, VA: NCTM.

Jordan, N. C., Kaplan, D., Nabors Oláh, L., \& Locuniak, M. N. (2006). Number sense growth in kindergarten: A longitudinal investigation of children at risk for mathematics difficulties. Child development, 77(1), 153-175. http://dx.doi.org/10.1111/j.1467-8624.2006.00862.x

Maertens, B., Reynvoet, B., De Smedt, B., \& Elen, J. (2014). Can training on one number sense skill be generalized to overall improved number sense? Results from an intervention study with a new tablet game. Paper presented at the World Conference on Educational Multimedia. Hypermedia and Telecommunications.

McIntosh, A., Reys, B. J., \& Reys, R. E. (1992). A proposed framework for examining basic number sense. For the Learning of Mathematics, 2-44.

National Council of Teachers of Mathematics. (2000). Principles and standards for school mathematics: An overview. Reston, VA: Author.

Olanoff, D., Hillen, A. F., Tobias, J. M., Welder, R. M., Thanheiser, E., \& Feldman, Z. (2014). Facilitating prospective teachers' fraction number sense development through problem solving and problem posing. Paper presented at the PME 38 / PME-NA 36, Vancouver, Canada.

Reys, R. E., \& Yang, D.-C. (1998). Relationship between computational performance and number-sense among sixth-and eighth-grade students in Taiwan. Journal for Research in Mathematics Education, 29(2), 225-237. http://dx.doi.org/10.2307/749900

Siegler, R. S., \& B. Ramani, G. (2011). Improving low-income children's number sense. In S. Dehaene, \& E. M. Brannon (Eds.), Space, time and number in the brain (pp. 343-354). San Diego: Academic Press.

Sweller, J., Van Merrienboer, J. J. G., \& Paas, F. G. W. C. (1998). Cognitive architecture and instructional design, Educational Psychology Review, 10(3), 251-297. http://dx.doi.org/10.1023/A:1022193728205

Waits, B. \& Demana, F. (1998). 1998 Math teacher educator short course, 1998 Teachers teaching with technology program. Columbus, Ohio: The Ohio State University.

Walcott, C., \& Stickles, P. R. (2012). Calculator use on NAEP: A look at fourth- and eighth- grade mathematics achievement. School Science and Mathematics, 112(4), 241-254. http://dx.doi.org/10.1111/j.1949-8594.2012.00140.x

Wheatley, G. H., \& Clements, D. H. (1990). Calculators and constructivism. Arithmetic Teacher, 38(2), 22-23.

Witzel, B. S., Ferguson, C. J., \& Mink, D. V. (2012). Number sense: Strategies for helping preschool through grade 3 children develop math skills. Young Children, 67(3), 89-94.

Yang, D. C. (2005). Number sense strategies used by 6th grade students in Taiwan. Educational Studies, 31(3), 317-333. http://dx.doi.org/10.1080/03055690500236845 
Yang, D.-C., \& Wu, W.-R. (2010). The study of number sense: Realistic activities integrated into third-grade math classes in Taiwan. The Journal of Educational Research, 103(6), 379-392. http://dx.doi.org/10.1080/00220670903383010

Yang, D. C., \& Lai, M. L. (2013). Teaching Benchmark Strategy for Fifth-Graders in Taiwan. Journal of Education and Learning, 2(2), 69-77. http://dx.doi.org/10.5539/jel.v2n2p69

\section{Notes}

Note 1. An earlier version of the paper was presented at PME 29th conference as a research report.

\section{Copyrights}

Copyright for this article is retained by the author(s), with first publication rights granted to the journal.

This is an open-access article distributed under the terms and conditions of the Creative Commons Attribution license (http://creativecommons.org/licenses/by/3.0/). 